\title{
Volar Plate Avulsion of PIP Joint: An Unusual Fielding Injury in Cricket
}

\author{
${ }^{1}$ Sharad Prabhakar, ${ }^{2}$ Himmat Singh Dhillon, ${ }^{3}$ Kevin Syam, ${ }^{4}$ Sidak Singh Dhillon, ${ }^{5}$ Mandeep Singh Dhillon
}

\begin{abstract}
Fielding injuries are the predominant contact injury in cricket, with the fingers taking the blunt of the trauma due to direct hit by the ball while taking catches. Many types of hand and finger injuries like soft tissue contusions, fractures/dislocations and ligament and joint sprains have been observed in this popular team sport. One of the unique kind of hand injuries associated with cricket is the avulsion of the volar plate of the proximal interphalangeal joint (PIP). Here, we report this unusual injury in a 24-year-old cricketer, its management and 3-month follow-up along with a review of hand injuries in cricket.
\end{abstract}

Keywords: Cricket injuries, Fielding injuries, Finger injuries, Hand injuries, Upper limb, Volar plate avulsion.

How to cite this article: Prabhakar S, Dhillon HS, Syam K, Dhillon SS, Dhillon MS. Volar Plate Avulsion of PIP Joint; An Unusual Fielding Injury in Cricket. J Postgrad Med Edu Res 2015;49(4):209-212.

\section{Source of support: Nil}

Conflict of interest: None

\section{INTRODUCTION}

Even though cricket is a non-contact sport, contact injuries do occur in a number of ways. ${ }^{1}$ One of the common injuries noticed in this team sport are hand injuries, especially sustained by the fielders. Among the various soft tissue and bony injuries, an unusual and rare injury sustained while fielding is the avulsion of the volar plate of the proximal interphalangeal joint (PIP joint). The knowledge about the possibility of such an injury is important as lack of recognition and delay in appropriate treatment may lead to chronic dorsal instability, pain and disability. ${ }^{2}$

\footnotetext{
${ }^{1}$ Assistant Professor, ${ }^{2}$ Resident, ${ }^{3}$ Senior Resident

${ }^{4}$ Senior House Surgeon, ${ }^{5}$ Professor

${ }^{1,3,5}$ Department of Orthopedics, Postgraduate Institute of Medical Education and Research, Chandigarh, India

${ }^{2}$ Department of Physiotherapy, Flinders University, Adelaide Australia

${ }^{4}$ Department of Orthopedics, Government Medical College and Hospital, Chandigarh India
}

Corresponding Author: Kevin Syam, Senior Resident Department of Orthopedics, Postgraduate Institute of Medical Education and Research, Chandigarh, India, Phone: 9855723399, e-mail: vinky_scorpio@yahoo.com
Early diagnosis and treatment assumes even further importance in such sport personnel who indulge in professional level matches. Here, we present a case of volar plate avulsion of the PIP joint in a 24-year old cricketer.

\section{CASE REPORT}

A 24-year old cricketer sustained an injury to the PIP joint of the middle finger of his right hand, while attempting to catch the cricket ball. The ball struck the tip of his middle finger, taking it into hyperextension, with immediate swelling and pain over the PIP joint, and reduced range of motion.

On examination, there was swelling at the right middle finger, maximally at PIP joint, with bruising evident on the volar surface of the joint. Proximal interphalangeal joint (PIP Joint) and the middle phalanx were tender, more so on the volar aspect. A fracture of the phalanx was suspected. Hand radiographs, however, did not show any fracture. Magnetic resonance imaging revealed a distal avulsion of the volar plate from the base of the middle phalanx (Fig. 1). Additionally, there were gradeIIlateraland medial collateral ligament tears. His finger was immobilized in extension (Fig. 2). Gentle passive stretching exercises were started at 3 weeks post injury. The player was off the game with his finger immobilized in an extension splint for 6 weeks following which he resumed his game. At 3 months follow-up, he is still playing with a strapped finger and has only minimal pain and swelling.

\section{DISCUSSION}

Cricket the most popular sport in India, has evolved from a staid game played over 5 days, to a hectic tussle between two teams over 50 overs and recently to the power packed Twenty twenty matches. This has led to an absolute increase in the amount of cricket being played by teams at professional level as there has been no concurrent reduction in the amount of first class or 50-over One Day Cricket being played in addition to the T-20 competitions. Effectively, the workload of the players has increased which has placed greater demands on cricketers due to the increased playing hours and increased performance expectations. ${ }^{1}$ As limited overs matches are often decided by a few runs, fielders are regularly required to dive and take risky catches, resulting in injuries. 


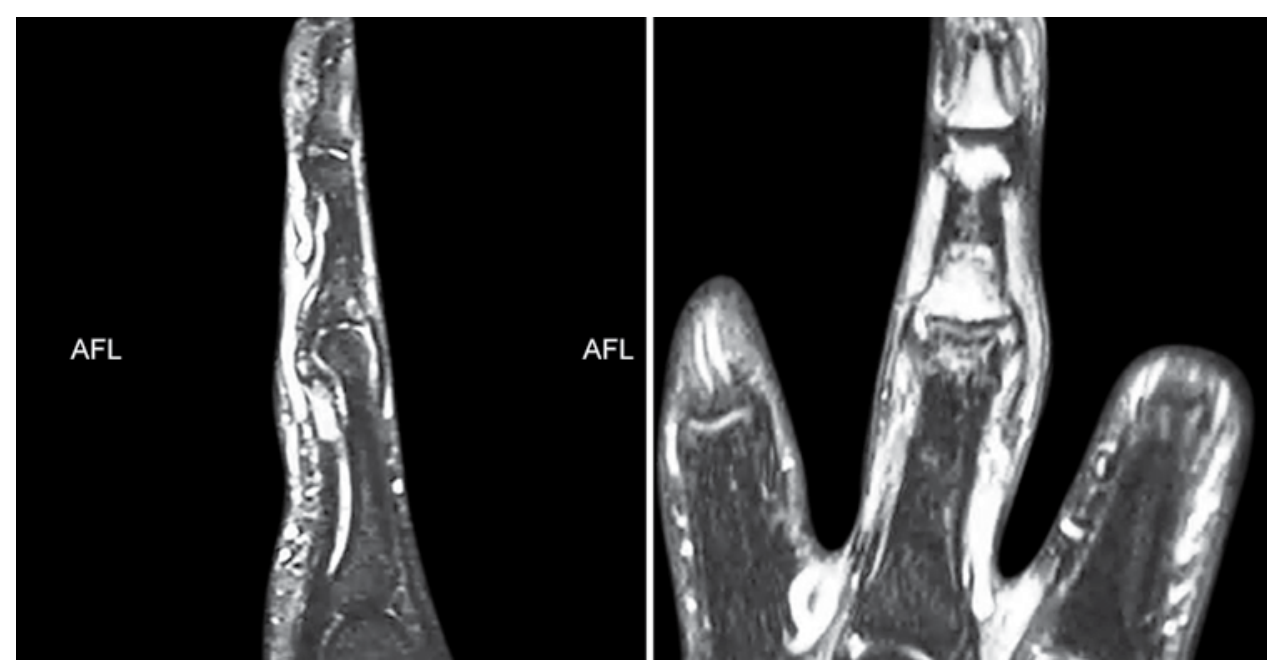

Fig. 1: Magnetic resonance imaging of hand showing distal avulsion of the volar plate from the base of the middle phalanx

The anatomical sites of injuries in cricket have been reported by various studies. Injuries to the lower limbs varied from 22.8 to $50.0 \%{ }^{3,4}$ Upper limb injuries accounted for 19.8 to $34.1 \%$ of total injuries, with the fingers found to be the most vulnerable site. ${ }^{4,5}$ Finger injuries generally occurred as a result of being struck by the ball during fielding, catching and batting. A literature review by the authors, regarding hand injuries in cricket revealed only a few relevant studies (Table 1). In the study by Dhillon et $\mathrm{al}^{6}$, most of the upper limb injuries were sustained during fielding and $62.5 \%$ of these injuries were severe enough to prevent the cricketer from returning to play for more than 4 weeks.

In the present report, we highlight an unusual fielding injury, the diagnosis of which may not come to mind immediately.

The PIP joint is a simple hinge and receives most of its stability from the surrounding soft tissue structures. ${ }^{14}$ The capsule is reinforced in a box-like fashion by the collateral and accessory collateral ligaments laterally, and the volar plate anteriorly. ${ }^{14}$ The function of the volar plate

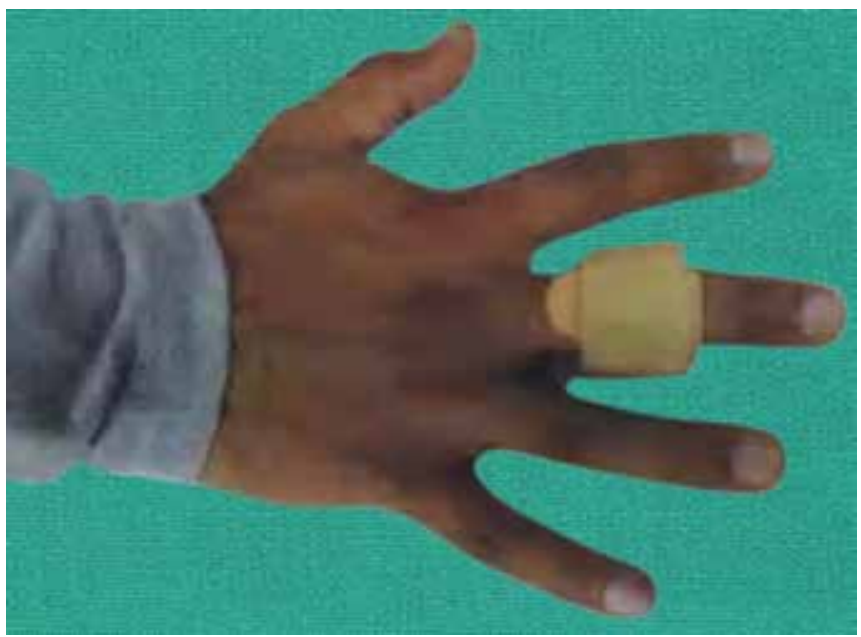

Fig. 2: Immobilization of the proximal interphalangeal joint in extension is largely to stabilize the joint in the anterior-posterior (AP) plane and resist hyperextension. ${ }^{14}$ It forms a strong distal attachment to the periosteum of the middle phalanx, while the proximal portion just attaches to the capsule. ${ }^{14,15}$

Volar plate avulsion is a hyperextension injury, which is essentially a ligamentous injury ${ }^{14}$ with avulsion more likely to occur at the distal attachment. ${ }^{14,15}$ This is commonly caused by a dorsally directed force applied to the tip of a finger, when a ball hits it. ${ }^{14}$ It may also involve a portion of bone avulsed off the base of the middle phalanx by the volar plate that is usually not significantly displaced and usually heals well. Significant avulsions (i.e. the bony fragment is more than $30 \%$ of the articular surface of the joint) may need to be fixed back if picked early, but the diagnosis is often delayed, as most cricketers tend to ignore small swellings of the hand. Delayed surgeries to fix the fragment have no added advantage. Diagnosis, following history and examination is easily made with the aid of a lateral $X$-ray projection of the joint in case of a bony avulsion. ${ }^{14,15}$ But in case of a ligamentous injury, MRI is required to reach a conclusive diagnosis. Volar plate avulsions are also usually associated with collateral ligament injury; which often heals with abundant scar tissue leading to an appearance of a permanent chronic swelling on one side of the joint.

There is a range of opinions regarding the optimal treatment for volar plate injuries. Non-surgical methods are the treatment of choice for small, stable volar plate avulsions. ${ }^{15-18}$ Surgical corrections are warranted only in cases with large bony avulsions, associated dorsal instability of the PIP joint and recurrent/neglected volar plate injuries. ${ }^{2,19}$ Surgical interventions are faced with difficulties of excessive tissue scarring and insufficiency of the volar plate tissue especially with increasing chronicity. Late volar plate repairs are technically demanding 
Table 1: Review of hand injuries in cricket

\begin{tabular}{|c|c|c|c|c|c|}
\hline S. no. & Authors & Study Period & Hand injury incidence & $\begin{array}{l}\text { Fielding injury incidence } \\
\text { to upper limb }\end{array}$ & $\begin{array}{l}\text { Fielding hand } \\
\text { injury incidence }\end{array}$ \\
\hline 1. & Stretch $\mathrm{RA}^{7}$ & $1998-1999$ to $2000-2001$ & $67 / 189(35.4 \%)$ & $27 / 67(40.6 \%)$ & NA \\
\hline 2. & Orchard $\mathrm{J}$, et al ${ }^{8}$ & $1995-1996$ to $2000-2001$ & $56 / 527(11 \%)$ & $25 / 60(41.7 \%)$ & $17 / 60(28 \%)$ \\
\hline 3. & Mansingh $\mathrm{A}$, et $\mathrm{al}^{9}$ & 2003-2004 & $11 / 50(22 \%)$ & $3 / 14(21.4 \%)$ & $2 / 14(14.2 \%)$ \\
\hline 4. & Ahearn $\mathrm{N}$, et al ${ }^{10}$ & $2008-2009$ to $2012-2013$ & $55 / 64(86 \%)$ & $33 / 64(52 \%)$ & NA \\
\hline 5. & Dhillon $\mathrm{MS}$, et al ${ }^{6}$ & 2008-2009 & $11 / 16(68.8 \%)$ & $10 / 16(62.5 \%)$ & $9 / 16(56.3 \%)$ \\
\hline 6. & Leary $\mathrm{T}$, et $\mathrm{al}^{11}$ & 1985-1995 & $135 / 990(13.6 \%)$ & NA & NA \\
\hline 7. & Sadleir LG, et al ${ }^{12}$ & 1987 & $33 / 520(6.3 \%)$ & NA & NA \\
\hline 8. & Belliappa PP, et al ${ }^{5}$ & - & 64 cases & NA & NA \\
\hline 9. & Dhillon MS, et al ${ }^{13}$ & Case report & - & - & - \\
\hline
\end{tabular}

surgeries for the aforementioned reasons and surgeons may have to resort to reconstruction procedures and flexor digitorum superficialis tenodesis procedure. ${ }^{2,19}$ The outcomes of such procedures are still inconclusive and further studies are required to determine the efficacy of these surgical interventions. All these stress, the importance of early recognition and appropriate conservative management of such injuries.

Among the conservative methods of treatment, some advocate immobilization with extension splints, others advocate neighbor strapping and yet others vote for early active mobilization. A randomized controlled trial conducted by Paschos et $\mathrm{al}^{16}$ to compare the efficacy of buddy strapping and aluminium orthosis for treatment of PIP joint hyperextension injuries, revealed similar outcomes between the two interventions. It was further noted that buddy strapping allowed earlier recovery of motion and resolution of edema and pain compared with aluminium orthosis immobilization. Two other trials that were identified suggest that early mobilization leads to acceptable functional outcomes. ${ }^{15,17}$ In another study, Incavo et $\mathrm{al}^{18}$ employed a technique of immobilization of the joint in full extension for 7 to 10 days using aluminium or orthoplastic splints, followed by a period of buddy strapping. The rationale was to avoid flexion contracture, while also attempting to minimize the risk of hyperextension instability. Good functional results were reported with conservative treatment with no cases of hyperextension instability in all of these studies. Even though immobilization is necessary in the acute scenario, it is important to work on obtaining full range of motion of the joint to achieve good functional outcome. ${ }^{20}$

In the present case, gentle passive stretching exercises were started at 3 weeks post injury. The player was off the game with his finger immobilized in an extension splint for 6 weeks following which he resumed his game. At 3 months follow-up, he is still playing with a strapped finger and has minimal pain and swelling.

\section{CONCLUSION}

Avulsion fractures of the volar plate at the PIP joint have a good treatment outcome especially when picked up early. Treatment should aim to prevent complications, while maximizing functional outcome. Currently, there is no good evidence to suggest that either early mobilization or initial splinting and immobilization is superior. Further randomized controlled trials are needed to fully assess this. Players can usually go back to cricket within 6 weeks but rehabilitation has to continue. The pain on contact may be persisting up to 6 months.

\section{REFERENCES}

1. Finch CF, Elliott BC, McGrath AC. Measures to prevent cricket injuries: an overview. Sports Med 1999 Oct;28(4):263-272.

2. Melone CP Jr, Polatsch DB, Beldner S, Khorsandi M. Volar plate repair for posttraumatic hyperextension deformity of the proximal interphalangeal joint. Am J Orthop (Belle Mead NJ) 2010 Apr;39(4):190-194.

3. Stretch RA. The incidence and nature of injuries in club and provincial cricketers. S Afr Med J 1993 May;83(5):339-341.

4. Stretch RA. Incidence and nature of epidemiological injuries to elite South African cricket players. S Afr Med J 2001 Apr;91(4): 336-339.

5. Belliappa PP, Barton NJ. Hand injuries in cricketers. J Hand Surg Br 1991 May;16(2):212-214.

6. Dhillon MS, Garg B, Soni RK, Dhillon H, Prabhakar S. Nature and incidence of upper limb injuries in professional cricket players a prospective observation. Sports Med, Arthrosc, Rehab, Ther Technol 2012 Nov;4(1):42.

7. Stretch RA. Cricket injuries: a longitudinal study of the nature of injuries to South African cricketers. Br J Sports Med 2003 Jun;37(3):250-253.

8. Orchard J, James T, Alcott E, Carter S, Farhart P. Injuries in Australian cricket at first class level 1995/1996 to 2000/2001. Br J Sports Med 2002 Aug;36(4):270-275.

9. Mansingh A, Harper L, Headley S, King-Mowatt J, Mansingh G. Injuries in West Indies cricket 2003-2004. Br J Sports Med 2006 Feb;40(2):119-123.

10. Ahearn N, Bhatia R, Griffin S. Hand and wrist injuries in professional county cricket. Hand Surg 2015;20(1):89-92.

11. Leary $\mathrm{T}$, White JA. Acute injury incidence in professional county club cricket players (1985-1995). Br J Sports Med 2000 Apr;34(2):145-147. 
12. Sadleir LG, Horne G. Indoor cricket finger injuries. N Z Med J 1990 Jan 24;103(882):3-5.

13. Dhillon MS, Singh S, Aggarwal S, Dhillon H. Multiple stress lesions in the dominant hand of a professional spin bowling cricketer: case report. J Sports Traumatol Allied Sci 2007;8:1-5.

14. Freiberg A, Pollard B, Macdonald M, Duncan MJ. Management of proximal interphalangeal joint injuries. J Trauma 1999 Mar; 46(3):523-528.

15. Gaine WJ, Beardsmore NF. Early active mobilisation of volar plate avulsion fractures. Injury 1998 Oct;29(8):589-591.

16. Paschos NK, Abuhemoud K, Gantsos A, Mitsionis GI, Georgoulis AD. Management of proximal interphalangeal joint hyperextension injuries: a randomized controlled trial. J Hand Surg Am 2014 Mar;39(3):449-454.
17. Phair IC, Quinton DN, Allen MJ. The conservative management of volar avulsion fractures of the PIP joint. J Hand Surg (Br) 1989 May;14(2):168-170.

18. Incavo SJ, Mogan JV, Hilfrank BC. Extension splinting of palmar plate avulsion injuries of the proximal interphalangeal joint. J Hand Surg Am 1989 Jul;14(4):659-661.

19. Kaneshiro Y, Hidaka N, Fukuda M, Ota M, Akashi K. Late volar plate repair for chronic, post-traumatic hyperextension deformity of the proximal interphalangeal joint of the little finger. J PlastSurg Hand Surg 2015;49(4):238-241.

20. Weber DM, Kellenberger CJ, Meuli M. Conservative treatment of stable volar plate injuries of the proximal interphalangeal joint in children and adolescents: a prospective study. Pediatr Emerg Care 2009 Sep;25(9):547-549. 